\title{
«МАЛЫЕ» ИсПОЛНИТеЛИ
}

\section{научных

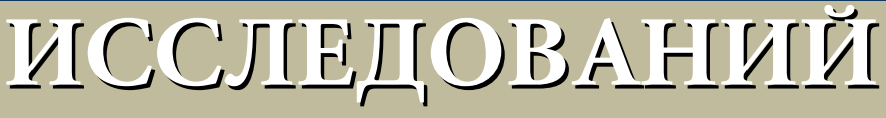 \\ EI PABPAEOTOK}

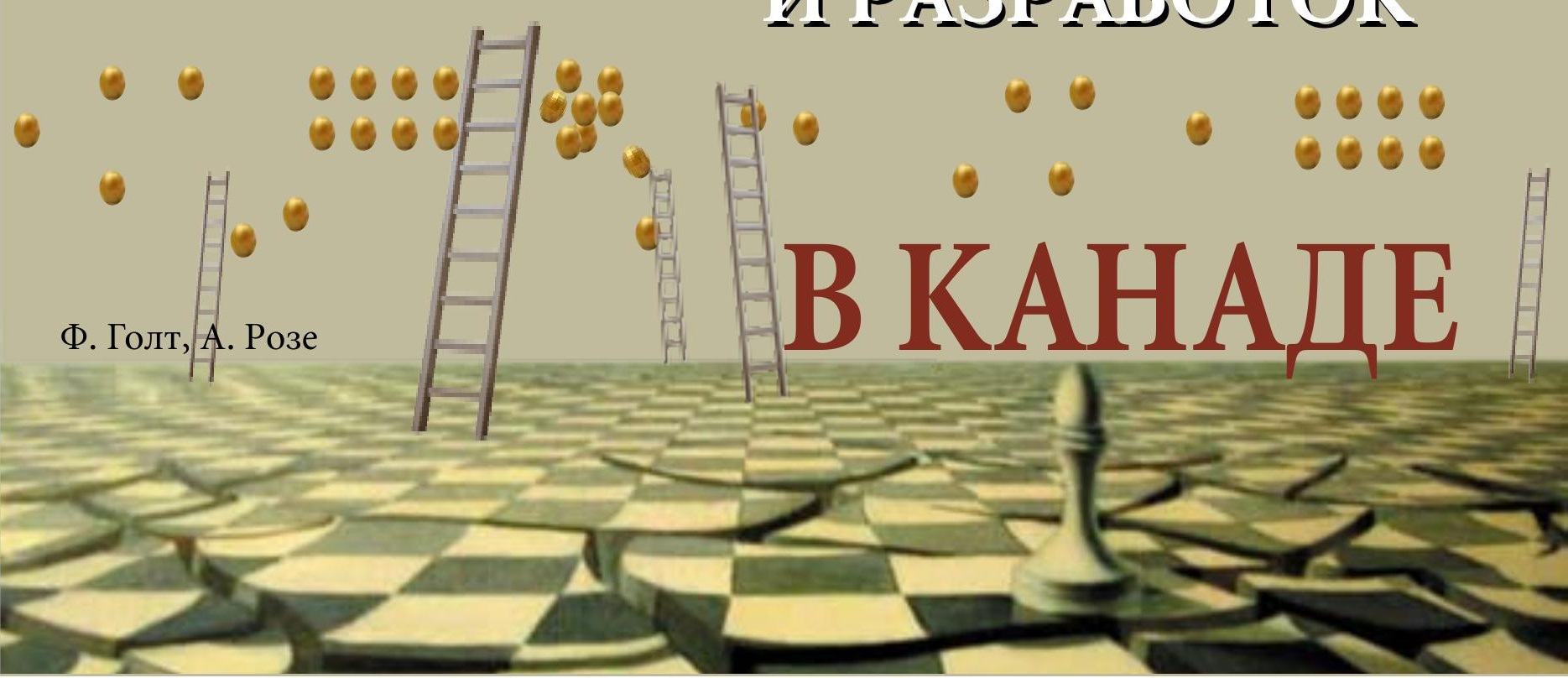

Из всех организаций Канады, осуществлянщих научные исследования и разработки (НИиР), более половины составлягт «малые» исполнители, то есть компании, расходующие на эту деятельность менее 100 тыс. долл. в год. В этот обширный сегмент входят компании всех размеров (как по численности работников, так и по объему доходов), и в нем занято семь процентов всего персонала, выполняющего НИиР. Но в то же время на долю малых исполнителей приходится лишь два процента общих расходов на НИиР в канадском частном секторе.

В статье обсуждаютося факторы, мотивируюиие данные компании к проведению НИиР, источники финансирования этих работ, использование в них человеческих ресурсов и способы трансформации полученных знаний 8 добавленную стоимосmb.

Уаучные исследования и разработки (НИиР) - фор1 мальный процесс создания новых знаний. Для целей статистики он определяется в «Руководстве Фраскати» следующим образом [1, p. 30]:

«Исследования и экспериментальные разработки представляют собой творческую деятельность, осущестиляемую на систематической основе с изелью увеличения запаса знаний, включая знания о человеке, культуре и обществе, и поиска новых способов применения этих знаний».

В развитых странах сбор официальной статистической информации о расходах на НИиР уже более сорока лет ведется в соответствии с упомянутым «Руководством Фраскати», которое выдержало за это время шесть переизданий. Собранные данные позволяют проводить международные сопоставления валовых внутренних расходов на исследования и разработки (GERD) и их соотношений с валовым внутренним продуктом (GDP) GERD/GDP - по всем странам ОЭСР. Для специалистов в области научно-технологической политики рейтинг стран на основе пропорции GERD/GDP служит важным индикатором потенциального роста благосостояния через инновации. Особый интерес вызывают оценки затрат на НИиР в предпринимательском секторе (BERD) и их соотношения с GDP (BERD/GDP).

Согласно данным ОЭСР за 2005 год [2], Канада занимает 12-е место по показателю GERD/GDP и 15-е - по соотношению BERD/GDP. Хотя по доле в GDP аналогичных расходов в секторе высшего образования (HERD/GDP) Канада находится на втором месте, инновационная политика тем не менее исходит из того, что основным источником роста национального благосостояния является предпринимательский сектор, а именно - создаваемые в нем знания. Конечно, 
Таблица 1. Концентрация затрат на НИиР в Канаде: 2002

\begin{tabular}{|l|r|r|}
\hline & \multicolumn{1}{|c|}{$\begin{array}{c}\text { BERD } \\
\text { (млн долл.) }\end{array}$} & \multicolumn{2}{|c|}{$\begin{array}{c}\text { Доля } \\
\text { BERD } \\
\text { (\%) }\end{array}$} \\
\hline Tоп 5 & 2567.6 & 19.2 \\
Топ 10 & 3248.7 & 24.3 \\
Топ 25 & 4680.9 & 35.0 \\
Топ 50 & 6029.8 & 45.1 \\
Топ 75 & 6875.5 & 51.4 \\
Топ 100 & 7466.0 & 55.9 \\
Всего компаний & 13366.5 & 100.0 \\
\hline Источник: [4]. & & \\
\hline
\end{tabular}

НИиР - не единственный источник знаний, применяемых компаниями для создания новых продуктов и, как следствие, добавленной стоимости, но этот вопрос здесь не рассматривается. Показатель BERD/GDP был и остается предметом заботы национальной инновационной политики Канады.

Данная статья посвящена тем компаниям, которые, вне зависимости от их размера, расходуют относительно малые средства на формальное наращивание знаний. Малые исполнители НИиР, которые вовсе не обязательно являются малыми по размеру компаниями, рассматриваются как часть общего исследовательского пространства Канады.

\section{НИиР в предпринимательском секторе Канады}

Первое, что бросается в глаза при изучении затрат бизнеса на исследования и разработки в Канаде, да и в большинстве других промышленно развитых стран, - то, что основная доля этих расходов обеспечивается небольшим числом фирм (табл. 1). И хотя уровень этой концентрации в течение последних двадцати лет снизился в Канаде с максимальных 68\%, приходившихся на 75 крупнейших компаний в 1984 году, до 51-53\% в последние годы [3], их доля по-прежнему превышает половину таких затрат. Это означает, что 75 руководителей способны оказывать существенное влияние на показатель BERD. Остальная часть BERD приходится примерно на 12 тыс. фирм, которые ведут значительно меньше исследований и экспериментальных разработок.

В Канаде существует правительственная программа по предоставлению компаниям налоговых кредитов на проведение НИиР в области естественных и технических наук, но на социальные или гуманитарные дисциплины она не распространяется. В рамках этой программы, инициированной Канадским агентством государственных сборов (Canada Revenue Agency - CRA), обеспечивается 35\%-й возмещаемый налоговый кредит для малых предприятий, управляемых гражданами Канады, и 20\%-й - для других предприятий, вне зависимости от их размера или национальной принадлежности [5]. В некоторых провинциях существуют аналогичные налоговые инструменты на местном уровне.

Не все компании обращаются за налоговой льготой, поскольку некоторые малые предприятия считают подобные запросы обременительными и к тому же опасаются дать дополнительный повод для налоговой проверки. Тем не менее, полагая, что большинство компаний пользуется налоговой скидкой, а также принимая во внимание, что определение термина НИиР, которым руководствуется CRA, очень близко к данному в «Руководстве Фраскати» и взятому на вооружение Статистической службой Канады, последняя может уменьшить бремя отчетности малых исполнителей НИиР, получая данные о поступлениях от них в CRA. Статистические обследования охватывают только те компании, которые ежегодно выполняют НИиР в Канаде на сумму, превышающую 1 млн долл. Информация о них представлена в таблице 2. При высоком уровне концентрации расходов на НИиР не удивительно, что $87 \%$ из них приходится на $10 \%$ таких компаний.

Канадский контроль над малыми предприятиями - обязательное условие CRA для предоставления более высокого и возвращаемого налогового кредита. Ранее исходили из того, что большинство малых фирм в стране находятся под управлением канадцев, и вопрос национальной принадлежности играл существенную роль только для более крупных компаний [6]. По данным за 2002 год, в стране действовали 388 фирм, управляемых иностранным капиталом (табл. 3), на долю которых приходилась треть общих расходов бизнеса на исследования и разработки. В среднем в одной такой компании в НИиР было задействовано 66 сотрудников (в компаниях, управляемых канадцами, - в среднем 7 человек). Это согласуется с тем, что канадские компании, занимающиеся НИиР и контролируемые иностранцами, крупнее аналогичных компаний с местными владельцами.

Размер компании - один из факторов, определяющих ее активность в сфере НИиР. Согласно данным таблицы 4, 88\% компаний, ведущих такую деятельность, имеют менее 100 работников, а непосредственно НИиР здесь занято в среднем не более 11 чел. На них приходится 23\% объема BERD и 40\% персонала, занятого НИиР. Для сравнения: более крупных компаний, с числом сотрудников 1000 и более, насчитывается всего 2\%, но на них приходится почти половина объемов BERD, треть научных кадров, а НИиР в них, как правило, занимается более сотни служащих.

Другая отличительная черта Канады состоит в том, что многие компании осуществляют НИиР в очень малых объемах. Если взять верхний порог в 100 тыс. долл., что соответствует годовым затратам на одного технического сотрудника, то 53\% компаний, ведущих НИиР в Канаде, попадет в эту категорию. На их долю приходится $2 \%$ объема BERD и 7\% исследовательского персонала предпринимательского сектора. В таких фирмах НИиР занимается всего 1-1.5 сотрудника (табл. 5). Именно эти компании и являются объектом нашего анализа.

\section{Постоянство малых исполнителей НИиР}

В работе Р.Шеллингса и Ф.Голта [7] рассматривались данные обо всех компаниях Канады, выполнявших НИиР в течение 9-летнего периода - с 1994 по 2002 год. Каждый год обследование охватывало от 10 до 13 тыс. компаний, а всего в нем собраны данные по 31 тыс. различных компаний. В статье показано, что чем выше объем уже выполненных компанией НИиР, тем больше 
Таблица 2. Данные по компаниям и объемам затрат на НИиР: 2002

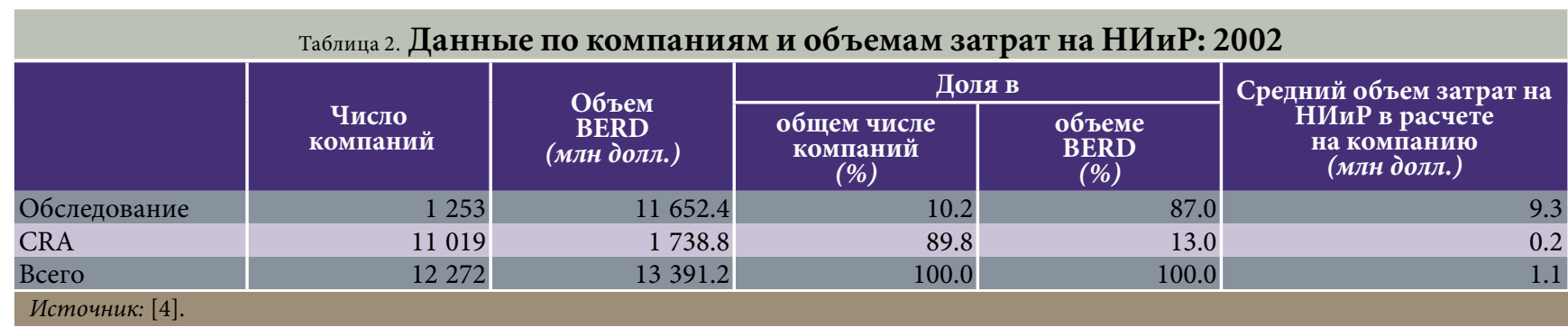

вероятность того, что они будут продолжаться в последующие годы. Из всех охваченных обследованием компаний, тех, что выделяли на эту деятельность менее 100 тыс. долл. в год и отмечены лишь один раз (в течение одного года), было 25\%, еще $16 \%$ таких компаний были отмечены дважды в течение девяти лет (соответственно 39\% и 25\% от всех компаний с объемом НИиР менее 100 тыс. долл. в год). Суммарная статистика по этим двум группам говорит о высокой волатильности при таких малых масштабах выполнения НИиР.

Обнаружилось также, что среди малых исполнителей НИиР расходы на исследовательскую деятельность тем выше, чем большее число лет фирма присутствует в результатах обследования. Средняя величина расходов увеличивается от 35 тыс. долл. для компаний, попавших в обследование лишь единожды, до 91 тыс. долл. для компаний, которые оставались в списках в течение шести лет. Возникает вопрос: с какими целями осуществлялись НИиР теми компаниями, которые занимались ими лишь кратковременно, конвертировались ли их результаты в добавленную стоимость, и если да, то каким образом?

В упомянутом выше обследовании не рассматривался вопрос о том, какие из малых исполнителей НИиР употребили знания, полученные ими в ходе этих работ, для того, чтобы избежать заказа значительно более дорогих исследований у сторонних организаций. Характеристики таких малых компаний должны очень существенно отличаться от присущих фирмам, которые не стали отказываться от привлечения исследовательских услуг со стороны[8].

Понимание активности малых исполнителей НИиР важно для федеральной политики в отношении исследовательской деятельности в предпринимательском секторе. По оценкам Р. Шеллингса и Ф. Голта [7], из 1766 компаний, которые изначально появились в их исследовании с расходами на НИиР менее 100 тыс. долл. в год, 29 спустя девять лет увеличили затраты по этой статье до 1 млн долл. и более, тогда как 1250 компаний прекратили работы такого рода.
В целом число компаний, выполняющих НИиР на сумму менее 100 тыс. долл. в год, - величина переменная. Хотя с компаниями, появляющимися в этой сфере на один или два года, не все ясно, тем не менее, существует небольшая вероятность того, что некоторые из них будут расти и трансформируются в крупных исполнителей НИиР, дающих существенный вклад в объем BERD. М.Бордт и др. [9] изучали роль НИиР как фактора, способствующего росту малых и средних предприятий, но все исследованные ими фирмы расходовали на эти цели более 100 тыс. долл. в год, а малые исполнители авторами не рассматривались.

Интерес вызывает деятельность тех малых исполнителей НИиР, которые извлекают пользу из результатов исследований и разработок посредством их коммерциализации.

\section{Компании с малыми объемами НИиР: данные специальных обследований}

В 2006-2007 годах были проведены интервью с представителями 40 малых и средних компаний. Их спрашивали о том, выполняются ли в их компаниях НИиР эпизодически либо на постоянной основе и обращались ли они при этом за налоговым кредитом $[10,11]$.

Обследование показало, что в тех случаях, когда НИиР осуществлялись не на регулярной основе, такие работы, как правило, инициировались либо самой компанией для решения внутренних задач, либо по заказу клиентов, нуждавшихся в помощи. В обоих случаях поводом для проведения НИиР оказывалась конкретная задача, требующая решения, и эта деятельность не носила постоянного характера.

Компании, выполнявшие НИиР, обращались за налоговым кредитом, предоставляемым по программе CRA, причем некоторые из них выражали озабоченность по поводу толкования приведенного выше определения НИиР чиновниками из Агентства, но не самого определения. Хотя указанные обращения получали положительный отклик, льготы не всегда предоставля-

Таблица 3. Показатели компаний, выполняющих НИиР, по национальности контроля: 2002

\begin{tabular}{|c|c|c|c|}
\hline & \multicolumn{2}{|c|}{ Контроль } & \multirow{2}{*}{ Всего } \\
\hline & Канадский & Иностранный & \\
\hline Число компаний & 11884 & 388 & 12272 \\
\hline BERD (млн долл.) & 9010.5 & 4356.0 & 13366.5 \\
\hline Численность персонала, выполняющего НИиР (чел.) & 87852 & 25556 & 113408 \\
\hline \multicolumn{4}{|l|}{ В процентах от: } \\
\hline общего числа компаний & 96.8 & 3.2 & 100.0 \\
\hline общего объема BERD & 67.4 & 32.6 & 100.0 \\
\hline общей численности персонала, выполняющего НИиР & 77.5 & 22.5 & 100.0 \\
\hline Средний объем затрат на НИиР в расчете на компанию (млн долл.) & 0.8 & 11.2 & 1.1 \\
\hline Средняя численность персонала, выполняющего НИиР, в расчете на компанию (чел.) & 7.4 & 65.9 & 9.2 \\
\hline
\end{tabular}


Таблица 4. Показатели компаний, выполняющих НИиР, по численности работников: 2002

\begin{tabular}{|c|c|c|c|c|c|c|c|c|}
\hline $\begin{array}{l}\text { Числен- } \\
\text { ность ра- } \\
\text { ботников } \\
\text { (чел.) }\end{array}$ & $\begin{array}{c}\text { Число } \\
\text { компаний }\end{array}$ & $\begin{array}{c}\text { Доля в } \\
\text { общем } \\
\text { числе } \\
\text { компаний } \\
(\%)\end{array}$ & $\begin{array}{c}\text { Oбъем } \\
\text { BERD } \\
\text { (млн } \\
\text { долл.) }\end{array}$ & $\begin{array}{c}\text { Доля в } \\
\text { общем } \\
\text { объеме } \\
\text { BERD } \\
(\%)\end{array}$ & \begin{tabular}{|} 
Численность \\
персонала, \\
вышолня- \\
ющего НИиР \\
(чел.)
\end{tabular} & $\begin{array}{c}\text { Доля в общей } \\
\text { численности } \\
\text { персонала, вы- } \\
\text { полняющего } \\
\text { НИиР } \\
\text { (\%) }\end{array}$ & $\begin{array}{c}\text { Средний объем } \\
\text { затрат на НИиР } \\
\text { в расчете на } \\
\text { компанию } \\
\text { (тыс. долл.) }\end{array}$ & $\begin{array}{c}\text { Средняя } \\
\text { численность пер- } \\
\text { сонала, выполня- } \\
\text { ющего НИиР, в } \\
\text { расчете на компа- } \\
\text { нию } \\
\text { (чел.) }\end{array}$ \\
\hline $0-9$ & 5177 & 42.2 & 581.6 & 4.4 & 10612 & 9.4 & 112.3 & 2.0 \\
\hline $10-19$ & 2168 & 17.7 & 419.5 & 3.1 & 7974 & 7.0 & 193.5 & 3.7 \\
\hline $20-49$ & 2281 & 18.6 & 975.5 & 7.3 & 14384 & 12.7 & 427.7 & 6.3 \\
\hline 50-99 & 1125 & 9.2 & 1144.9 & 8.6 & 11913 & 10.5 & 1017.7 & 10.6 \\
\hline $100-199$ & 708 & 5.8 & 1183.3 & 8.9 & 11604 & 10.2 & 1671.3 & 16.4 \\
\hline $200-499$ & 441 & 3.6 & 1235.2 & 9.2 & 11275 & 9.9 & 2800.9 & 25.6 \\
\hline 500-999 & 155 & 1.3 & 1258.6 & 9.4 & 9358 & 8.3 & 8120.0 & 60.4 \\
\hline $1000-1999$ & 114 & 0.9 & 1862.1 & 13.9 & 11616 & 10.2 & 16334.2 & 101.9 \\
\hline $2000-4999$ & 60 & 0.5 & 1299.6 & 9.7 & 8310 & 7.3 & 21660.0 & 138.5 \\
\hline > 4999 & 43 & 0.4 & 3406.3 & 25.5 & 16362 & 14.4 & 79216.3 & 380.5 \\
\hline Всего & 12272 & 100.0 & 13366.6 & 100.0 & 113408 & 100.0 & 1089.2 & 9.2 \\
\hline
\end{tabular}

лись им в запрошенном объеме. Подтверждение тому можно найти, например, в «Обследовании применения и развития биотехнологии в Канаде» [12], которое охватило 532 инновационные компании в данной сфере. В общей сложности они потратили на научные исследования 1703 млн долл., что составило $41 \%$ от их доходов. При анализе поведения малых исполнителей НИиР с учетом заявок, поданных ими в федеральную программу CRA, выявились два примечательных факта (табл. 6). Во-первых, не все малые исполнители (хотя и большинство) информировали Агентство о стоимости реализуемых ими НИиР. Во-вторых, заявляемая в Агентство доля затрат на выполняемые НИиР снижается с ростом общего объема этих работ. В первом случае причина, возможно, кроется в том, что не все компании знакомы с федеральной программой и порядком подачи заявок. То же самое может относиться и к крупным исполнителям НИиР, хотя здесь отчасти играет роль иная структура предоставляемых льгот для крупных фирм, что также ведет к снижению числа обращений за налоговыми скидками. Как уже отмечалось, малые компании (с годовым доходом до 200 тыс. долл.), находящиеся под канадским контролем, получают 35\%-й налоговый кредит на ведение НИиР, поэтому для них выгодно подавать подобные заявки. Более крупные канадские компании, а также компании, контролируемые иностранцами, имеют право только на 20\%-й налоговый кредит. Чтобы извлечь вы- году из такой льготы, компания должна благодаря НИиР в определенный момент выйти на получение налогооблагаемых доходов. Вряд ли это возможно для биотехнологических компаний, выполняющих НИиР на сумму более 100 тыс. долл., поскольку для продвижения их продукции на рынке через систему регулирующих органов требуются годы. Даже у тех компаний, которые уже предлагают свою продукцию на рынке, расходы могут все еще превышать доходы.

Для проведения НИиР имеются и другие источники финансирования, помимо нераспределенной прибыли и налоговых кредитов (возвращаемых и невозвращаемых). Существуют гранты, заказы и субсидии со стороны правительства и других учреждений, например банков развития и частных некоммерческих организаций, поддерживающих исследования в сфере здравоохранения. Эти источники не являются независимыми, поскольку поступления из федерального бюджета меняют величину налоговых кредитов, за которыми может обратиться компания. В качестве других потенциальных источников выступают средства частных лиц и компаний - бизнес-ангелов, венчурных капиталистов и коммерческих банков.

Проведенный анализ позволяет выделить требующие дальнейшего изучения аспекты деятельности малых исполнителей НИиР: 1) источники мотивации (внутренние факторы, аффилированные компании,

\begin{tabular}{|c|c|c|c|c|c|c|c|c|}
\hline $\begin{array}{l}\text { Затраты на } \\
\text { НИиР } \\
\text { (тыс. долл.) }\end{array}$ & \begin{tabular}{|} 
Число \\
компаний
\end{tabular} & $\begin{array}{c}\text { Доля } \\
\text { в общем } \\
\text { числе } \\
\text { компаний } \\
(\%)\end{array}$ & $\begin{array}{c}\text { Объем } \\
\text { BERD } \\
\text { (млн } \\
\text { долл.) }\end{array}$ & $\begin{array}{c}\text { Доля в } \\
\text { общем } \\
\text { объеме } \\
\text { BERD } \\
(\%)\end{array}$ & $\begin{array}{c}\text { Численность } \\
\text { персонала, } \\
\text { выполня- } \\
\text { ющего НИиР } \\
\text { (чел.) }\end{array}$ & $\begin{array}{c}\text { Доля в общей } \\
\text { численности } \\
\text { персонала, вы- } \\
\text { полняющего } \\
\text { НИиР } \\
(\%)\end{array}$ & $\begin{array}{c}\text { Средний объем } \\
\text { затрат на НИиР } \\
\text { в расчете на } \\
\text { компанию } \\
\text { (тьс. долл.) }\end{array}$ & $\begin{array}{c}\text { Средняя } \\
\text { численность пер- } \\
\text { сонала, выполня- } \\
\text { ющего НИиР, в } \\
\text { расчете на } \\
\text { компанию } \\
\text { (чел.) }\end{array}$ \\
\hline $0-24$ & 2094 & 17.1 & 28.0 & 0.2 & 2093 & 1.8 & 13.4 & 1.0 \\
\hline $25-49$ & 1948 & 15.9 & 70.8 & 0.5 & 2012 & 1.8 & 36.3 & 1.0 \\
\hline 50-99 & 2389 & 19.5 & 172.6 & 1.3 & 3702 & 3.3 & 72.2 & 1.5 \\
\hline $100-199$ & 2182 & 17.8 & 310.8 & 2.3 & 6338 & 5.6 & 142.4 & 2.9 \\
\hline 200-399 & 1411 & 11.5 & 396.5 & 3.0 & 7801 & 6.9 & 281.0 & 5.5 \\
\hline 400-999 & 1077 & 8.8 & 659.8 & 4.9 & 11660 & 10.3 & 612.6 & 10.8 \\
\hline $1000-1999$ & 456 & 3.7 & 635.6 & 4.8 & 9609 & 8.5 & 1393.9 & 21.1 \\
\hline $2000-9999$ & 510 & 4.2 & 2147.5 & 16.1 & 21292 & 18.8 & 4210.8 & 41.7 \\
\hline$>9999$ & 205 & 1.7 & 8944.9 & 66.9 & 48901 & 43.1 & 43633.7 & 238.5 \\
\hline Всего & 12272 & 100.0 & 13366.5 & 100.0 & 113408 & 100.0 & 1089.2 & 9.2 \\
\hline
\end{tabular}




\begin{tabular}{|c|c|c|c|c|}
\hline \multicolumn{5}{|c|}{$\begin{array}{r}\text { Таблица 6. Использование федеральных налоговых кредитов инновационными } \\
\text { биотехнологическими компаниями: } 2005\end{array}$} \\
\hline $\begin{array}{c}\text { Затраты на НИиР } \\
\text { (mыс. долл.) }\end{array}$ & Число компаний & $\begin{array}{c}\text { Заявки на } \\
\text { предоставление } \\
\text { налоговых кредитов } \\
\text { (мыс. долл.) }\end{array}$ & $\begin{array}{c}\text { Общий объем затрат } \\
\text { на НИиР } \\
\text { (тыс. долл.) }\end{array}$ & $\begin{array}{c}\text { Доля заявок на } \\
\text { предоставление налоговых } \\
\text { кредитов в затратах на НИиР } \\
(\%)\end{array}$ \\
\hline $1-99$ & 28 & 1481 & 1697 & 87.3 \\
\hline $100-999$ & 161 & 30275 & 64861 & 46.7 \\
\hline 1000 и более & 216 & 563234 & 2277185 & 24.7 \\
\hline Всего & 405 & 594990 & 2343743 & 25.4 \\
\hline
\end{tabular}

клиенты, поставщики, конкуренты и т.д.); 2) порядок проведения (разовый, на постоянной основе); 3) источники финансирования (собственные средства, аффилированные компании, клиенты, поставщики, правительственное налоговое стимулирование, заказы, гранты, пожертвования и др.); 4) трудности, связанные с теми или иными источниками финансирования.

Возникают и вопросы, касающиеся жизнеспособности малых исполнителей НИиР и их возможностей преобразовывать знания, полученные в ходе этих работ, в добавленную стоимость. Компании, отвечающие на запросы клиентов, способны продавать свои услуги и продолжать деятельность в выбранной сфере бизнеса. Компаниям же, которые инициируют НИиР по собственной инициативе, при уровне вложений ниже 100 тыс. долл., вероятно, придется предпринимать специальные усилия, чтобы сохранить свои позиции в бизнесе. Понимание взаимоотношений малого исполнителя НИиР с рынком требует особого акцента.

Частично развитие исследовательской деятельности в компании определяется наличием высококвалифицированных инженеров или ученых и их технической обеспеченностью. Учитывая, что малые исполнители имеют в штате в среднем не более полутора сотрудников, занятых НИиР (табл. 5), информация о характеристиках этих работников приобретает критическое значение для анализа поведения компаний.

\section{Инновации и НИиР}

До сих пор в центре нашего внимания были компании, выполнющие НИиР на сумму менее 100 тыс. долл. Вместе с тем в рамках обследования инновационной деятельности за 2005 год, предпринятого Ста- тистической службой Канады [13], были рассмотрены взаимосвязи между инновациями и НИиР в сфере промышленного производства и лесозаготовок. Обследование охватило компании с доходом не менее 250 тыс. долл. и численностью работников не менее 20 чел. Полученные результаты свидетельствуют, что $66 \%$ предприятий осуществляют инновации на минимальном уровне новизны, выпуская продукцию, новую лишь для самой компании, но не для рынка [14]. Из числа инновационных компаний $82 \%$ выполняли исследования и разработки за счет собственных средств, но только 49\% обращались за федеральными налоговыми кредитами. Среди предприятий, которые не участвовали в инновационном процессе, число заявителей составляло 12\%, что позволяет предположить осуществление ими НИиР, но не инноваций, востребованных рынком. Эти компании не обязательно относились к категории малых исполнителей НИиР, тем не менее, очевидно, что использование инструментов федеральной программы налоговых кредитов положительно коррелирует с инновациями. Это говорит о важности изучения путей, которыми знание, полученное в ходе НИиР малыми исполнителями, выходит на рынок и коммерциализируется.

Проведенное исследование демонстрирует необходимость более глубокого анализа деятельности компаний, выполняющих НИиР в малых масштабах, но составляющих при этом более половины исполнителей НИиР в Канаде. Требуется осознание условий, обеспечивающих большее постоянство малых исполнителей в осуществлении исследовательской деятельности и успешную коммерциализацию накопленных результатов. Авторы будут информировать читателей журнала «Форсайт» о ходе последующих исследований.

1. Frascati Manual: Proposed Standard Practice for Surveys on Research and Experimental Development. Paris: OECD, 2002.

2. Main Science and Technology Indicators, vol. 2007/1. Paris: OECD, 2007.

3. Industrial Research and Development, 2005 Intentions, Catalogue № 88-202-XIE. Ottawa: Statistics Canada, 2006.

4. Schellings R. Industrial R\&D Statistics by Region 1994 to 2003, Catalogue № 88F0006XIE, № 017. Ottawa: Statistics Canada, 2005.

5. Scientific Research and Experimental Development (SR\&ED) Tax Incentive Program: Supporting Canadian Innovation. CRA, 2007. www.cra-arc.gc/taxcredit/sred/menu-e.html.

6. The Effect of Country of Control on Industrial Research and Development (R\&D) Performance in Canada 1993, Catalogue № 88-001, vol. 21, № 2. Ottawa: Statistics Canada, 1997.

7. Schellings R., Gault F. Size and Persistence of R\&D Performance in Canadian Firms: 1994 to 2004, Catalogue № 88F0006XIE, № 008. Ottawa: Statistics Canada, 2006.

8. Rose A. Transfers of Funds for Research and Development in Canadian Industry - 1993, Catalogue № 88F0006XIE, № 005. Ottawa: Statistics Canada, 1997.

9. Bordt M., Anderson F., Earl L., Lonmo C., Bas T. Innovation and Components of Growth in Canadian Firms. In: Earl L., Gault F. (Eds.) National Innovation, Indicators and Policy. Cheltenham, UK: Edward Elgar, 2006.

10. Commercialization and R\&D Impacts. A collaborative research project between Industry Canada and Statistics Canada: Interview Guide. Statistics Canada, 2006. http://www.statcan.ca/english/sdds/instrument/5140_Q1_V1_E.pdf.

11. Rosa J., Rose A. Report on Interviews on Commercialization of Innovation, Catalogue № 88F0006XIE, № 004. Ottawa: Statistics Canada, 2007.

12. Biotechnology Use and Development Survey, The Daily, January 30, 2007. Statistics Canada, 2007. http://dissemination.statcan.ca/Daily/English/070130/d070130c.htm.

13. Survey of Innovation 2005 (preliminary), The Daily, June 2, 2006. Statistics Canada, 2006.

http://dissemination.statcan.ca/Daily/English/060602/d060602d.htm.

14. Oslo Manual: Guidelines for Collecting and Interpreting Innovation Data. Paris: OECD/Eurostat, 2005. 